\title{
Initial Experience With Transurethral Enucleation With Bipolar Energy for Benign Prostatic Hyperplasia
}

\author{
Dae Young Kim, Dae Hyoung Park, Chun Ha Hwang, Jong Bouk Lee, Jong Hyun Yoon, \\ Tae Wook Jeong, Woong Na \\ Department of Urology, National Medical Center, Seoul, Korea
}

Corresponding Author: Woong $\mathrm{Na}, \mathrm{MD}, \mathrm{PhD}$ Department of Urology, National Medical Center, 245, Eulji-ro, Jung-gu, Seoul 04564, Korea

Tel: $+82-2-2260-7252$

Fax: +82-2-2274-6601

E-mail: woong224@gmail.com
Background: This retrospective study examined the safety and efficacy of transurethral enucleation with bipolar energy (TUEB) for benign prostatic hyperplasia (BPH), based on initial experiences. Methods: In this study, 2 surgeons performed TUEB on 23 patients between January 2014 and April 2017. The International Prostate Symptom Score (IPSS), quality of life (QoL), digital rectal examination, transrectal ultrasonography, prostate-specific antigen (PSA) levels, maximum flow rate (Omax), and postvoid residual urine (PVR) were used as variables. Resected prostate volume (g), resection time, efficiency of resection, change in hemoglobin, and indwelling Foley catheter duration were used to assess the efficacy of TUEB. Foley catheter reinsertion rate, occurrence of urethral or bladder neck stricture, urinary incontinence, and bladder injury were evaluated as complications of TUEB. Results: Mean age was $70.3 \pm 8.3$ years. Mean prostate volume was $55.1 \pm 33.9 \mathrm{~g}$. Preoperative and 1-month postoperative PSA, IPSS, QoL, Omax, and PVR data were collected and showed significant difference. Resected prostate volume, resection time, resection efficiency, indwelling Foley catheter duration, and change in hemoglobin values were $22.9 \pm 14.7 \mathrm{~g}, 109.6 \pm 60.3$ minutes, $0.23 \pm 0.13 \mathrm{~g} / \mathrm{min}, 4.7 \pm 4.7$ days, and $0.9 \pm 0.7 \mathrm{~g} / \mathrm{dL}$, respectively. Following TUEB, incontinence occurred in 2 patients and acute urinary retention in 2 (8.7\%). Conclusion: Our initial experience suggests that TUEB is efficient and safe for patients with BPH. However, the study was limited by the small number of subjects.

\section{Key Words: Benign prostatic hyperplasia, Transurethral enucleation with bipolar}

Received: September 9, 201 Revised: October 26, 2017 Accepted: October 26, 2017

\section{INTRODUCTION}

As the elderly male population increases, interest in improving the quality of life ( $\mathrm{OoL})$ has also increased. The prevalence of benign prostatic hyperplasia (BPH) has correspondingly increased. Pharmacological treatment primarily includes 5-alpha-reductase inhibitors and alpha blockers. If these are not effective or if urinary retention, urinary tract infection, and bladder stones occur, surgical treatment is considered $^{1,2)}$. Transurethral resection of the prostate (TURP) has been considered standard surgery for BPH. However, complications of TURP include retrograde ejaculation, bleeding requiring transfusion, and metabolic disorders due to internal resorption of irrigation fluid in 15\%-20\% of elderly patients ${ }^{3)}$. Accordingly, recent studies on less invasive and more effective techniques have been performed. In 1998, Gilling and Fraundorfer ${ }^{4)}$ introduced holmium laser enucleation of the prostate (HoLEP), which was found to be safe and effective, with less bleeding and fewer complications compared to TURP. Transurethral enucleation with bipolar energy (TUEB) is expected to have therapeutic efficacy and safety similar to those of HoLEP. Research on TUEB has been actively conducted in other countries, but there have been few studies on its safety and efficacy in Korea. Accordingly, the authors present their initial experience with 23 patients who underwent TUEB for BPH, and analyze treatment efficacy.

\section{MATERIALS AND METHODS}

\section{Subjects and Methods}

The study included outpatients in the Urology Department with lower urinary tract symptom and was conducted between January 2014 and April 2017. BPH diagnosis was based on urinalysis, blood tests, prostate-specific antigen (PSA) level, transrectal ultrasonography (TRUS), digital rectal examination (DRE), maximum flow rate (Omax), and postvoid residual urine (PVR). The International Prostate Symptom Score (IPSS) and IPSS-OoL score were assessed. Among 26 patients who 
underwent TUEB for $\mathrm{BPH}, 2$ with recurrences requiring a different procedure and 1 with prostate cancer were excluded. Finally, 23 patients were analyzed. An increase in PSA above $4.0 \mathrm{ng} / \mathrm{mL}$, a palpable nodule on DRE, or the presence of a hypoechoic lesion was an indication for TRUS-guided prostate biopsy before surgery. Resected prostate volume (g), resection time ( $\mathrm{min})$, resection efficiency $(\mathrm{g} / \mathrm{min})$, indwelling Foley catheter duration (days), change in postoperative hemoglobin, and complications during surgery were evaluated. Need for Foley catheter reinsertion, urinary tract infection, urethral stricture, bladder neck contracture, urinary incontinence, and bladder injury were examined 1 month postoperatively, and the IPSS, QoL, PSA, Omax, and PVR values results were used to evaluate treatment effect. Surgery was performed by 2 surgeons, and this retrospective survey was based on review of medical records. This study was approved by the institutional Review Board of the National Medical Center (approval number: $\mathrm{H}-1707-080-005)$ and a written informed consent was exempted.

\section{Operative Technique}

The Olympus SurgMaster (Olympus Winter \& Ibe $\mathrm{GmbH}$, Hamburg, Germany) was used for TUEB. The procedure consisted of transurethral resection in a saline medium using a standard loop electrode and tungsten wire loop with an attached spatula and normal saline for irrigation. All patients underwent surgery in lithotomy position under epidural or general anesthesia. A 26-Fr continuous-flow resectoscope was inserted to examine the bladder and determine the size and shape of the prostate and verumontanum. A standard loop electrode was used to resect the prostate at 12,5 , and 7 o'clock positions. A bilateral, circumferential mucosal incision was made on the apical prostatic adenoma. A spatula attached to a wire loop was used to push the prostatic ade- noma to the bladder neck, for enucleation from the surgical capsule. Mushroom-shaped tissue was not completely excised, but was enucleated to the extent of remaining attached near the ladder neck. Hemostasis was performed in conjunction with enucleation ${ }^{5}$. The prostatic adenoma attached to the bladder neck was resected into small pieces with a standard loop electrode (Fig. 1). Resected tissue was removed from the bladder with an Ellik evacuator, and a 22-Fr Foley catheter was inserted in all patients. Electrical current (Olympus Winter \& lbe $\mathrm{GmbH}$ ) was used for resection and hemostasis at $280 \mathrm{~W}$ and $100 \mathrm{~W}$, respectively.

\section{Statistical Analysis}

IBM SPSS Statistics ver. 19.0 (IBM Co., Armonk, NY, USA) was used for statistical analysis, and the Wilcoxon signed-rank test was used for pre- and postoperative data analysis. A $\mathrm{p}$-value less than 0.05 was considered significant.

\section{RESULTS}

Mean age of the 23 patients was $70.3 \pm 8.3$ years. Mean prostate volume was $55.1 \pm 33.9 \mathrm{~g}$ and adenoma volume was $25.9 \pm 19.5 \mathrm{~g}$. Mean preoperative PSA, Omax, PVR, IPSS, and OoL values were $8.3 \pm 11.9 \mathrm{ng} / \mathrm{mL}, 7.9 \pm 4.8 \mathrm{~mL} / \mathrm{sec}, 100.2 \pm 96.5$ $\mathrm{mL}, 28.0 \pm 2.7$, and 4.6 \pm 0.6 , respectively (Table 1). Eleven patients had a preoperative PSA $>4.0 \mathrm{ng} / \mathrm{mL}$, a palpable nodule on DRE, or a hypoechoic lesion, and TRUS-guided prostate biopsy was recommended. Six patients had a prior biopsy diagnosis of BPH or refused prostate biopsy; therefore, preoperative biopsy was performed in 5 patients. Among these, 1 was diagnosed with prostate cancer and 4 with $\mathrm{BPH}$. The average resected prostate size during surgery was $22.9 \pm 14.7 \mathrm{~g}$, and the operative time and resection efficiency were 109.6 \pm 60.3 minutes and $0.23 \pm 0.13 \mathrm{~g} / \mathrm{min}$ respectively. After surgery,

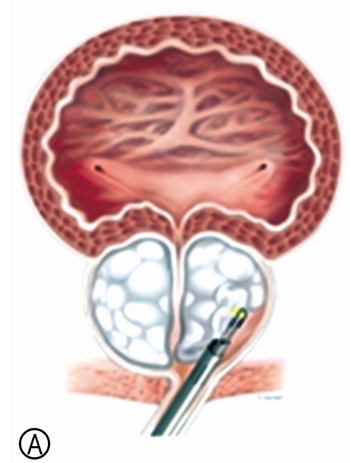

Fig. 1. Method of transurethral enucleation with bipolar. (A) After mucosa at the apical adenoma is incised circumferentially, both lateral lobes are enucleated using the transurethral enucleation with bipolar loop with bleeding coagulation. (B) Enucleation is continued until the adenoma is just hanging from the bladder neck. (C) Enucleated lobes are resected using a traditional electrocautery wire loop. Reprinted from Olympus catalog with permission of Olympus Korea Co. (Seoul, Korea). 
Dae Young Kim, et al.

a Foley catheter was placed in all patients and the mean indwelling catheter duration and changes in hemoglobin were $4.7 \pm 4.7$ days and $0.9 \pm 0.7 \mathrm{~g} / \mathrm{dL}$, respectively (Table 2 ). Bladder

Table 1. Baseline characteristics $(n=23)$

\begin{tabular}{lc}
\hline \hline Variable & Mean \pm SD \\
\hline Age $(\mathrm{yr})$ & $70.3 \pm 8.3$ \\
Prostate volume $(\mathrm{g})$ & $55.1 \pm 33.9$ \\
Adenoma volume $(\mathrm{g})$ & $25.9 \pm 19.5$ \\
PSA $(\mathrm{ng} / \mathrm{mL})$ & $8.3 \pm 11.9$ \\
Qmax $(\mathrm{mL} / \mathrm{sec})$ & $7.9 \pm 4.8$ \\
IPSS & $28.0 \pm 2.7$ \\
QoL & $4.6 \pm 0.6$ \\
PVR $(\mathrm{mL})$ & $100.2 \pm 96.5$ \\
\hline
\end{tabular}

SD, standard deviation; PSA, prostate-specific antigen; Qmax, maximum urinary flow rate; IPSS, International Prostate Symptom Score; QoL, quality of life; PVR, postvoid residual urine.

Table 2. Perioperative data $(n=23)$

\begin{tabular}{lc}
\hline \hline Variable & Mean \pm SD \\
\hline Resected weight $(\mathrm{g})$ & $22.9 \pm 14.7$ \\
Operative time (min) & $100.9 \pm 60.3$ \\
Operative efficiency (g/min) & $0.23 \pm 0.13$ \\
Catheterization time (day) & $4.7 \pm 4.7$ \\
Hemoglobin decrease (g/dL) & $0.9 \pm 07$ \\
Bladder injury (\%) & 0 \\
\hline
\end{tabular}

$\mathrm{SD}$, standard deviation.

Table 3. Comparison of pre- and postoperative data

\begin{tabular}{lccc}
\hline \hline Variable & Preoperative & $\begin{array}{c}\text { Postoperative } \\
(1 \mathrm{mo})\end{array}$ & p-value \\
\hline PSA $(\mathrm{ng} / \mathrm{mL})$ & $8.3 \pm 11.9$ & $2.1+2.4$ & $0.000^{*}$ \\
Qmax $(\mathrm{mL} / \mathrm{sec})$ & $7.9 \pm 4.8$ & $17.8 \pm 9.5$ & $0.000^{*}$ \\
PVR $(\mathrm{mL})$ & $100.2 \pm 96.5$ & $35.8 \pm 20.8$ & $0.000^{*}$ \\
IPSS & $28.0 \pm 2.7$ & $10.7 \pm 4.0$ & $0.000^{*}$ \\
QoL & $4.6 \pm 0.6$ & $2.2 \pm 0.8$ & $0.000^{*}$ \\
\hline
\end{tabular}

Values are presented as mean \pm standard deviation.

PSA, prostate-specific antigen; Qmax, maximum urinary flow rate; PVR, postvoid residual urine; IPSS, International Prostate Symptom Score; QoL, quality of life.

* $\mathrm{p}<0.05$, statistically significant difference.

Table 4. Intraoperative and postoperative complications

\begin{tabular}{lc}
\hline \hline Complications & Number (\%) \\
\hline Bladder injury & $0(0)$ \\
Recatheterization & $2(8.7)$ \\
Transient incontinence & $2(8.7)$ \\
Urinary tract infection & $0(0)$ \\
Urethral stricture & $0(0)$ \\
Bladder neck contracture & $0(0)$ \\
\hline
\end{tabular}

injury was not observed. At 1-month postoperatively, the mean PSA, Omax, PVR, IPSS, and OoL values were 2.1 \pm 2.4 $\mathrm{ng} / \mathrm{mL}, 17.8 \pm 9.5 \mathrm{~mL} / \mathrm{sec}, 35.8 \pm 20.8 \mathrm{~mL}, 10.7 \pm 4.0$, and $2.2 \pm 0.8$, respectively, indicating significant symptom improvement (Table 3).

Two cases (8.7\%) required Foley reinsertion due to early voiding failure after initial catheter removal and 2 cases $(8.7 \%)$ developed urinary incontinence. There were no cases of bladder injury, urethral stricture, or urinary tract infection. In the 2 cases with early voiding failure, the Foley catheter was removed 2-3 days after reinsertion and both voided successfully. In the 2 cases with urinary incontinence, pharmacological treatment, and behavior therapy resolved the symptoms (Table 4).

\section{DISCUSSION}

$\mathrm{BPH}$ is the most common urologic disease in males aged $\geq 50$ years. With aging of the population, the prevalence of $\mathrm{BPH}$ is increasing, and lower urinary tract symptoms due to BPH can substantially decrease the $\mathrm{OoL}^{6,7}$. TURP has been considered a standard treatment method for patients with $\mathrm{BPH}$, but can result in metabolic disorders due to bleeding or resorption of irrigation fluid ${ }^{3,8)}$. Accordingly, research on less invasive and safer techniques has been performed. After its introduction by Gilling and Fraundorfer ${ }^{4}$, , several studies verified the safety and efficacy of HoLEP, which was found to be more efficient for BPH than TURP, regardless of prostate size, with fewer indwelling Foley catheter and inpatient days $^{9-12)}$. However, a prolonged learning time is required for urologists who are accustomed to TURP. Moreover, the necessary instruments are expensive and there is a risk of bladder injury, as morcellation is performed within the bladder after resection of prostatic tissue. Therefore, hospitals do not consider HoLEP as a standard technique ${ }^{13)}$. Since its introduction by Hirasawa et al. ${ }^{5}$ ) as a more efficient technique compared to HoLEP, research on the safety and efficacy of TUEB has increased. TUEB instruments include a loop used for TUR, with an integrated spatula and bipolar electrode, similar to those used in TURP. A spatula attached to the loop is used for bilateral enucleation of the prostatic adenoma. Simultaneous hemostasis can be performed during enucleation with the bipolar electrode. The present authors have not encountered bleeding requiring transfusion. Moreover, in a study by Kawamura et al. ${ }^{14)}$ on 30 patients who underwent TUEB, there were no reported cases of bleeding requiring transfusion or reoperation. In addition, TUEB does not completely excise the enucleated adenoma, but instead leaves an attachment to the bladder neck, and then resects the tissue without pushing it into the bladder. The technique is similar to that of TURP with respect to the low risk of bladder injury. Moreover, the learning time is shorter than 
that of HoLEP for urologists used to TURP. TUEB is easily performed and expensive laser equipment is not required. A study by Placer et al. ${ }^{15)}$ on learning time and complications of HoLEP in $125 \mathrm{BPH}$ patients reported an initial mean operative time of 158 minutes in 25 patients. The authors noted that HOLEP has a longer average operative time than that of TUEB. Rieken et al. ${ }^{16)}$ reported that the bladder injury rate due to morcellation during HOLEP was $0.5 \%-18.2 \%$. However, the present research observed no cases of bladder injury after surgery. With regard to operative efficiency, the mean size of resected prostate with TUEB was $22.9 \mathrm{~g}$ and the resection efficiency was $0.23 \mathrm{~g} / \mathrm{min}$. In a study of learning time, efficacy, and safety of HoLEP by Hwang et al. ${ }^{177}$, the mean resection volume and efficiency in an initial 50 patients were $17.9 \mathrm{~g}$ and $0.25 \mathrm{~g} / \mathrm{min}$, respectively. A comparison of the initial experience with TUEB and HoLEP suggests that the operative efficiency can be increased as the experience with the techniques increases. A preoperative and 1-month postoperative comparison of symptom indicators in the present study showed significant improvement. However, 2 cases required catheter reinsertion $(8.7 \%)$, and 2 developed urinary incontinence (8.7\%). In comparison with Hwang et al.'s findings ${ }^{17)}$, there was no significant difference in the complication rates. Of 164 patients who underwent surgery in Hwang et al.'s study, catheter reinsertion was required in $13(7.9 \%)$ and urinary incontinence developed in $14(8.5 \%)$. In the present study, no cases of postoperative urinary tract infection, urethral stricture, or bladder neck contracture were observed; however, only complications at 1 month postoperatively were examined. According to the results reported by Hirasawa et al. ${ }^{5)}$ for TUEB in 55 patients, $2(3.6 \%)$ developed urethral strictures 6 months after surgery. In a study by Kawamura et al. ${ }^{14)}$ on TUEB in 30 patients, the reported urethral stricture rate was about $13 \%$ at 1 month after surgery. Accordingly, follow-up observation for the occurrence of postoperative complications is required.

In conclusion, this study reported the initial results of TUEB in $23 \mathrm{BPH}$ patients. The small number of patients in the study was a limitation. However, this technique was only recently introduced, and the worldwide experience is limited. The present authors consider TUEB to be safe and effective for BPH and expect that it will replace TURP. Further observation in a larger number of cases and research on safety and efficacy are required.

Conflicts of Interest Disclosures: The researchers claim no conflicts of interest.

\section{REFERENCES}

1. Kuo RL, Paterson RF, Kim SC, Siqueira Jr TM, Elhilali MM, Lingeman JE. Holmium laser enucleation of the prostate (HoLEP): a technical update. World J Surg Oncol 2003;1:6.
2. Moon KY, Kim DY, Yoon JH, Na W, Lee JB. Outcomes of the holmium laser enucleation of the prostate for patients with prior benign prostatic hyperplasia surgery. J Korean Geriatr Soc 2014; 18:199-204.

3. Mebust WK, Holtgrewe HL, Cockett AT, Peters PC. Transurethral prostatectomy: immediate and postoperative complications. A cooperative study of 13 participating institutions evaluating 3,885 patients. J Urol 1989;141:243-7.

4. Gilling PJ, Fraundorfer MR. Holmium laser prostatectomy: a technique in evolution. Curr Opin Urol 1998;8:11-5.

5. Hirasawa Y, Ide H, Yasumizu Y, Hoshino K, Ito Y, Masuda T. Comparison of transurethral enucleation with bipolar and transurethral resection in saline for managing benign prostatic hyperplasia. BJU Int 2012;110(11 Pt C):E864-9.

6. Goh HJ, Kim SA, Nam JW, Choi BY, Moon HS. Community-based research on the benign prostatic hyperplasia prevalence rate in Korean rural area. Korean J Urol 2015;56:68-75.

7. Seo DH, Kam SC. Recent advances in laser treatment for benign prostatic hyperplasia. J Korean Med Assoc 2017;60:401-8.

8. Rassweiler J, Teber D, Kuntz R, Hofmann R. Complications of transurethral resection of the prostate (TURP): incidence, management, and prevention. Eur Urol 2006;50:969-79.

9. Gilling PJ, Mackey M, Cresswell M, Kennett K, Kabalin JN, Fraundorfer MR. Holmium laser versus transurethral resection of the prostate: a randomized prospective trial with 1-year followup. J Urol 1999;162:1640-4.

10. Krambeck AE, Handa SE, Lingeman JE. Experience with more than 1,000 holmium laser prostate enucleations for benign prostatic hyperplasia. J Urol 2013;189(1 Suppl):S141-5.

11. Montorsi F, Naspro R, Salonia A, Suardi N, Briganti A, Zanoni $\mathrm{M}$, et al. Holmium laser enucleation versus transurethral resection of the prostate: results from a 2-center, prospective, randomized trial in patients with obstructive benign prostatic hyperplasia. J Urol 2004;172(5 Pt 1):1926-9.

12. Tan AH, Gilling PJ, Kennett KM, Frampton C, Westenberg AM, Fraundorfer MR. A randomized trial comparing holmium laser enucleation of the prostate with transurethral resection of the prostate for the treatment of bladder outlet obstruction secondary to benign prostatic hyperplasia in large glands (40 to 200 grams). J Urol 2003;170(4 Pt 1):1270-4.

13. Tracey JM, Warner JN. Transurethral bipolar enucleation of the prostate is an effective treatment option for men with urinary retention. Urology 2016;87:166-71.

14. Kawamura Y, Tokunaga M, Hoshino H, Matsushita K, Terachi T. Clinical outcomes of transurethral enucleation with bipolar for benign prostatic hypertrophy. Tokai J Exp Clin Med 2015; 40:132-6.

15. Placer J, Gelabert-Mas A, Vallmanya F, Manresa JM, Menéndez V, Cortadellas R, et al. Holmium laser enucleation of prostate: outcome and complications of self-taught learning curve. Urology 2009;73:1042-8.

16. Rieken M, Ebinger Mundorff N, Bonkat G, Wyler S, Bachmann A. Complications of laser prostatectomy: a review of recent data. World J Urol 2010;28:53-62.

17. Hwang JC, Park SM, Lee JB. Holmium laser enucleation of the prostate for benign prostatic hyperplasia: effectiveness, safety, and overcoming of the learning curve. Korean J Urol 2010;51: 619-24. 